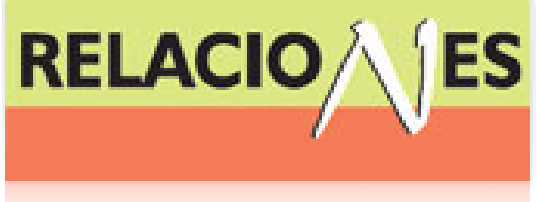

Relaciones. Estudios de historia y sociedad ISSN: 0185-3929

relacion@colmich.edu.mx

El Colegio de Michoacán, A.C

México

Bastos, Santiago

La nueva defensa de Mezcala: un proceso de recomunalización a través de la renovación étnica Relaciones. Estudios de historia y sociedad, vol. XXXII, núm. 125, 2011, pp. 87-122

El Colegio de Michoacán, A.C

Zamora, México

Disponible en: http://www.redalyc.org/articulo.oa?id=13718526004

- Cómo citar el artículo

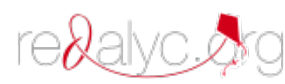

- Número completo

- Más información del artículo

Página de la revista en redalyc.org

Sistema de Información Científica

Red de Revistas Científicas de América Latina, el Caribe, España y Portugal Proyecto académico sin fines de lucro, desarrollado bajo la iniciativa de acceso abierto 


\title{
La nueva defensa de Mezcala: un proceso de recomunalización a través de la renovación étnica
}

\author{
Santiago Bastos*
}

CIESAS OCCIDENTE

El conflicto en que está inmersa Mezcala por las amenazas a su tierra comunitaria es el marco de una renovación de la idea misma de comunidad y de los contenidos de la identidad étnica. Ante el derrumbe del sistema posrevolucionario que dio cobijo a la territorialidad de Mezcala desde la legislación agraria, las nuevas propuestas asociadas a la idea de pueblos indígenas -en este caso el pueblo coca- están sirviendo para renovar los derechos territoriales y de autogobierno, pero también los contenidos del ser indígena y de la vida comunitaria.

(Comunidad, etnicidad, globalización, pueblos indígenas)

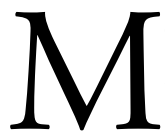

ezcala de la Asunción es un poblado situado en la ribera norte del lago de Chapala, perteneciente al municipio de dalajara. Aparte de la belleza de su emplazamiento, no llamaría especialmente la atención si no fuera porque en los últimos años se ha enzarzado en una pugna con los tres niveles de gobierno para defender la integridad de sus tierras comunales.

Este enfrentamiento forma parte de un proceso de renovación de la comunidad que, desde las bases agrarias posrevolucionarias está adaptándose al contexto creado tras el giro neoliberal-multicultural marcado por los cambios en los Artículos 4 y 27 constitucionales. Cuando el Estado mexicano ya no asegura la defensa del territorio, los mezcalenses echan mano de la historia y la identidad para sentirse pueblo coca y desde ahí reconstruir tanto el pacto co-

*santiagobastos@gmail.com 
munitario como su razón de ser ante la nueva legitimidad. Lo que está ocurriendo en Mezcala es un ejemplo de las dinámicas que se están desarrollando en muchas localidades de México, en que esa forma históricamente creada de comportamiento social que denominamos "comunidad" se está rearticulando en un contexto nuevo. ${ }^{1}$

\section{La Resolución Presidencial y el reconocimiento DEL TERritorio de Mezcala}

Mezcala obtuvo su reconocimiento legal como "Comunidad Indígena” a través de la Resolución Presidencial firmada por el presidente Luis Echevarría en 1971 y publicada en agosto de 1974, que "reconoce y titula a favor del poblado Mezcala una superficie de tres mil seiscientas dos hectáreas con veinte áreas" a las que declara "inalienables, imprescriptibles e inembargables” (Resolución Presidencial, 1971) de las que sólo los originarios de Mezcala pueden ser propietarios, y por las que no tienen que pagar ningún tipo de contribución al municipio.

\section{La Resolución como reconocimiento}

Culminaba así un proceso iniciado casi 20 años antes, cuando según la memoria local, una serie de ancianos y autoridades locales empe-

${ }^{1}$ Al hablar de "la comunidad" se piensa en un espacio social caracterizado por unos comportamientos colectivos - corporados según Wolf (1957)-, pero en que también se dan los "individualistas" supuestamente opuestos. Esta corporatividad es producto de una forma de entender las relaciones sociales que ha surgido de una historia concreta -en este caso de subordinación étnica (Bastos 2000)-. Por ello, "la comunidad" no es un espacio idílico de relaciones horizontales, sino el escenario de conflictos, luchas y desigualdades (Zárate 1996) que, eso sí, se dan dentro del marco comunitario de entenderlas. No se trata de un remanente de un pasado -glorioso o abyecto-, sino que se va construyendo como producto de su entorno y en estrecha relación con él. La cuestión no es tan fácil como una "comunidad" que sobrevive a los embates del Estado (Dietz 1999) ni como la reserva de fuerzas contra la globalización neoliberal (Díaz Polanco 2006). Como constructo histórico, esa forma de relaciones sociales que denominamos "comunidad", está siendo transformada en estos momentos: la globalización incide de tal forma en estas instituciones y comportamientos que podemos hablar de una forma comunitaria adaptada y producto del entorno global. 
zaron los trámites de "reconocimiento" de las tierras de la comunidad, que estaban sufriendo los embates de las localidades vecinas y empezaban a sentir la presión inmobiliaria desde la capital.

Como dice en el texto, la Resolución Presidencial sirvió para "reconocer y titular las tierras que la comunidad ha venido poseyendo en forma continua, pacífica y pública desde tiempo inmemorial” (ibid.). Esta frase-que en el documento sirve para salvaguardar las propiedades particulares que hubiera dentro del territorio- tenía para los mezcalenses un significado claro. No se trataba de la recuperación como "restitución" de unas tierras que se hubieran perdido previamente, y tampoco implicaba la "dotación" de nuevas tierras para los mezcalenses en forma de ejido. La autoridad competente -en este caso el Departamento de Asuntos Agrarios y Colonización- estaba sancionando oficialmente una propiedad que ya existía previamente, como ellos habían probado fehacientemente: "Los títulos presentados por los comuneros para acreditar la propiedad de sus terrenos fueron declarados auténticos por la Dirección General de Asuntos Jurídicos del Departamento de Asuntos Agrarios y Colonización” (ibid.)

\section{El Titulo Primordial}

Los "títulos" que en su momento presentaron los mezcalenses y a los que refiere la resolución son en realidad uno solo: el llamado "Titulo Primordial" o "Titulo Virreinal" que estaba en posesión de los principales de la comunidad y costó mucho recuperar para poder enviar a México -y de hecho aún no ha vuelto-. Se trata de un documento prolijo - 20 páginas de tamaño oficio en la versión mecanografiadasupuestamente fechado en 1539 y firmado por el virrey Mendoza en que se reconoce que "estos Poblados son Antigos de Inmemorial tiempo y moradores en este mismo suelo y angustura del Agua, de la Laguna chapalica, y de una Cierra, alta que esta al Norte". Después de la descripción de las tierras y sus linderos, se otorgan en "donación y Consención de dominio y derecho de estas Tierras, en perpetua posesión y lejitima propiedad de los naturales de este Pueblo, y de toda su generación". Por ello, se insiste varias veces en que el documento es para que "no sean despojados los Indios, posean sus 
tierras", dado que es una "espesial gracia y Mersed y Venta Real y Publica, para siempre jamas de aguas de tierras cerros y montes" (Título Primordial, 1899). ${ }^{2}$

Varios de los detalles del documento -nombres de personas y lugares, referencias históricas- hacen dudar de la autenticidad de la fecha de redacción. Según Castillero (2006), posiblemente fue redactado en el siglo XVII a tenor de las presiones que se sufrían por la política de composiciones de la Corona espańola, como tantos otros en esa época (Florescano 1999). ${ }^{3}$ De todas formas, Castillero (ibid.) muestra cómo la tierra mencionada fue poseída por Mezcala al menos desde el siglo Xvi.

La sanción oficial a la validez del Título aumentó más su valor simbólico dentro de la comunidad. A pesar de que nunca regresó de México, sigue siendo el documento base en que la comunidad de Mezcala cifra su propiedad sobre el territorio. La Resolución Presidencial de 1971 sólo corrobora algo que ya se poseía "desde tiempo inmemorial", renovando con el Estado mexicano un pacto que ya se había sellado con la Corona española: "con la posesión inmemorial de nuestro territorio, su defensa y el pago a los españoles fue como se tituló nuestro territorio. Por lo que ninguna ley, persona o gobierno podrá despojarnos, con este título somos los absolutos dueños, con legítimos derechos para siempre" (El pueblo coca de Mezcala. Una historia de lucha, 2008).

De todas formas, en la Resolución Presidencial el territorio reconocido es menor al mencionado en el Título Primordial. Posiblemente fue a lo largo del siglo XIX cuando se perdieron las tierras fértiles y planas ubicadas al norte de la cadena montańosa que rodea el pueblo, y llegaban hasta el río Santiago y el territorio adjudicado a Tlachichilco, que de Mezcala pasó a depender del vecino San Juan

${ }^{2}$ En la actualidad se sabe de tres "versiones" del Título: el "original" que está en el Archivo General -y al que parece que falta una página final-; una copia a máquina autenticada por un notario de La Barca en el ańo 1899 -que es la que se usa como fuente más habitual-y otra copia manuscrita realizada por don Malaquías Rosales, uno de los ancianos que presentó la solicitud de reconocimiento, y está en manos de sus familiares.

${ }^{3}$ Como en esos otros títulos similares, su valor está en que se trata de un documento creado por la misma comunidad, utilizando las formas de argumentación de la administración colonial para asegurar la posesión del territorio (Florescano 1999, 2002). 
Tecomatlán. ${ }^{4}$ Con ello, el actual territorio de la Comunidad Indígena de Mezcala está compuesto por una estrecha franja cultivable a la orilla de la laguna y un amplio macizo montańoso con escasa vocación agraria que rodea el pueblo. Y por algo más....

\section{La Isla y los insurgentes}

En el Acta del acto de "Reconocimiento y Titulación" de los bienes comunales, realizado el 17 de octubre de 1974, aparece un extraño acotamiento: "Como incidente al presente acto los comuneros asistentes al presente acto manifestaron que dentro de los títulos primordiales se encuentra la Isla de Mezcala (Isla Indómita), terrenos han poseído desde época inmemorial, por lo cual solicitan la pronta confirmación de la citada Isla”.

Esto llevó a la Comunidad a promover un juicio, que dio lugar a un "Acta de Deslinde y Amojonamiento Definitivo" que se llevó a cabo el 4 de septiembre de 1997, se puede leer: "Se hace la aclaración que la comunidad tiene en posesión además de la superficie que se deslinda la Isla de Mezcala que está ubicada como a 3,500 metros enfrente del pueblo dentro del lago de Chapala".

Esta insistencia muestra el valor que para los comuneros mezcalenses tiene a la isla situada frente al pueblo, conocida como Isla de Mezcala o Isla del Presidio, que es considerada -junto a la Isla Chica que hay a su costado- como parte integrante de su territorio comunitario. En el Título Primordial aparece con el nombre de "Isla de Tlaltequepetque" y de forma prolija se relata la forma en que se tomó posesión de ella:

[...] trajeron Canoas y sus remos y marineros de los indios y navegamos entre sus Aguas, y llegaron las canoas a su morro sur de la Isla y les hisimos grasia y mersed y donacion de esta Isla, que esta dentro de las Aguas dulses de esta Laguna Chapalica [...] en señal de esta posecion y amparo Caba-

${ }^{4}$ Mezcala sigue manteniendo una relación especial con Tlachichilco: es conocido como "el Barrio", forma parte de las ligas de futbol locales, y algunos mezcalenses tienen tierras ahí. 
ron la Tierra, tiraron piedras y buyeron sus Aguas y quedan dueños perpectuos de esta Isla (Título Primordial, 1899)

Y la verdad es que no es cualquier parte del territorio: pese a su condición excéntrica, es considerada como "el corazón de la comunidad”. De hecho, desde ella parte cada año la procesión con la que se inician las fiestas titulares del pueblo el 9 de agosto. ${ }^{5} \mathrm{Y}$, sobre todo, en la Isla se desarrolló un episodio histórico en el cual los mezcalenses cifran su orgullo local y consideran un momento más de la defensa del territorio.

Se trata de la "defensa de la Isla", ocurrida en los momentos más bajos de las luchas por la independencia, cuando entre 1812 y 1816 unos mil "indios de Mezcala" y otras localidades cercanas, dirigidos por un cura mestizo -Marcos Castellanos-y dos indios, uno del vecino Tlachichilco -Encarnación Rosas- y otro del mero Mezcala -José Santana-; resistieron el cerco de las tropas realistas. En los cuatro años siguientes fueron incapaces de desalojarlos de la pequeña isla y de impedir sus continuos ataques a poblaciones ribereñas. El armisticio con que se saldó el cerco conllevó la restitución de propiedades y es la base de un profundo orgullo local. El relato del momento refuerza esta sensación de triunfo:

[...] lo recibió con todas demostraciones de agrado, prometió q. les entregaría los Pueblos redificados, q. les pondría Bueyes, semillas y todo lo necesario para q. no tuviesen necesidades; q. los casarían, Bautizarían y enterrarían de balde; y q. finalmente, serían tratados con toda consideración [...] Los Isleños jamás quisieron rendirse, á esto los impelió el echo de allarse sin Gefes que los dirigiesen, y porq. Se les aseguró el cumplimiento de la capitulación, y de q. se les había nombrado a Santana de Gobernador con el grado de Tente. Coronel (Santoscoy 1986). ${ }^{6}$

${ }^{5}$ Posiblemente se trata de una pervivencia y actualización de los ritos que se practicaban antes de la llegada de los españoles en honor de la diosa o "ídolo" que en el Título Primordial aparece denominada Thonztil.

${ }^{6}$ Este texto es un fragmento del relato escrito por el mismo José Santana en 1825 a petición de las autoridades del recién creado Estado de Jalisco en 1825 y recogidos cincuenta ańos después por el historiador Alberto Santoscoy (1986). 
Este episodio ha sido objeto de estudios históricos (Pérez Verdía 1953; Archer 1998; Ochoa 1985, 2006; Castañeda 2005) y recreaciones noveladas (Aguirre 1966; Navarro 1999), y mantiene cierta presencia en la historia oficial regional y estatal. ${ }^{7}$ Pero para los mezcalenses es fundamental: todos los años, el 25 de noviembre -fecha del armisticio- es día feriado y toda la semana hay representaciones escolares del episodio. Además de los héroes locales -encabezados por "el Indio" José Santana-, de ese momento histórico proviene una de las frases-mito de la identidad mezcalense: "que corra el sangre" y también un orgullo fundamental: "nunca nos vencieron". Es decir, no se apropiaron de la isla que era su territorio. Este orgullo se trasplanta hasta las actuales circunstancias y es usada como reclamo identitario en momentos de conflicto:

tenemos que resistir como lo hicieron nuestros antepasados (Los coca de Mezcala siguen vivos, 2006)

La Isla, el corazón de la comunidad, símbolo de nuestra historia de resistencia, es la que ahora está más amenazada por la avaricia del hombre (Declaratoria de Mezcala, 2008)

\section{LA INSERCIÓN EN LAS INSTITUCIONES DEL MÉXICO POSREVOLUCIONARIO}

La titulación de las tierras comunales de Mezcala no se hizo entonces para recuperar tierras perdidas o para lograr unas nuevas que aliviaran la presión sobre las existentes; la función de este acto legal fue la de proteger con la legislación e institucionalidad republicana el territorio que la comunidad había venido utilizando desde la Colonia como propio.

Este acto de protección hizo cambiar las reglas internas de funcionamiento de la comunidad. Por lo que sabemos, hasta entonces todos los adultos -varones, podemos suponer-eran quienes elegían

${ }^{7}$ En el Palacio de Gobierno de Guadalajara, junto a los nombres de próceres jaliscienses aparecen los "Héroes Defensores de la Isla de Mezcala". En la localidad turística de Chapala un par de murales están dedicados a estos hechos. 
a las autoridades de la Comunidad, encabezados por un presidente -como el que aparece firmando la copia del Título de 1899-. Según se desprende de los testimonios de los ancianos, en las asambleas anuales en que se elegían, se renovaban también los Jueces de Barrio que se encargaban del orden y obras públicas como representantes del delegado -que era propuesto por la comunidad- en los nueve barrios en que históricamente se ha dividido Mezcala.

\section{La comunidad agraria}

A partir de este reconocimiento oficial, la tierra de la comunidad de Mezcala fue manejada por una nueva institución, también denominada "Comunidad Indígena de Mezcala" pero con una nueva estructura dictada por la legislación agraria nacional (Baitenmann 2007). Se basa la figura de los "comuneros" como propietarios colectivos, que se reúnen periódicamente en una Asamblea y escogen anualmente un Comisariado de Bienes Comunales dirigido por un presidente.

Pero sólo algunos de los mezcalenses pasaron a ser estos nuevos "comuneros" y con ello "dueños legítimos" del territorio. Cuando alrededor de 1960 se hizo el Censo Básico, por razones diversas -divisiones internas, presión de los caciques, desconfianza a la novedad-, sólo 406 mezcalenses - entre la mitad y un tercio de los que podrían haberlo hecho- se apuntaron en el "Censo Básico". Se trata seguramente de uno de los enfrentamientos locales que fueron tan habituales en los procesos de adjudicación y reconocimiento de tierras (Roseberry 2004; Escalona 2004; Baitenmann 2007). Las versiones escuchadas en la comunidad no muestran un escenario conflictivo, hablan de que mientras algunos pensaron que el reconocimiento era la mejor manera de asegurar la tenencia comunal, otros pensaran que era mejor seguir como se estaba, porque si la convertían en ejido, la dividirían. ${ }^{8}$ También se habla de la oposición de los caciques locales, que se dieron cuenta que esta iniciativa restringiría su poder al

${ }^{8}$ Este tipo de enfrentamiento entre "tradicionalistas" -que bucaban mantener la figura de la comunidad-y "agraristas" - que preferían solicitar tierras ejidales- se dio en lugares como Ayotitlán (Lucio et al., 2008). 
institucionalizar el control sobre la tierra. Pero es posible que algunos pensaran que era un buen momento para ya adjudicar la tierra en forma privada a cada uno. El caso es que la nueva Comunidad Indígena surgió como fruto de una división en la comunidad local.

Pero esta situación no afectó, la posibilidad del uso de las tierras reconocidas como sí ha ocurrido en otras comunidades (Baitenmann 2007). Si bien, legalmente sólo unos cuantos mezcalenses figuraron como los nuevos "propietarios" de las 3,600 hectáreas, todos los pobladores las siguieron usando como propias - no existe la figura del "avecindado"-. La Comunidad reguló el uso privado en el área de la ribera y casco urbano a través de la "hijuelas" y el uso colectivo en los cerros. En este sentido, las tierras son "comunales" porque son de la comunidad, no porque se utilicen comunitariamente; es algo parecido a lo que en otros lugares llaman "ejido común” (Velásquez 2004, 228): un uso privado por parte de todas las personas originarias y pertenecientes a la comunidad, que no sólo son los "comuneros", sino todo aquel que haya nacido en Mezcala.

\section{La ciudadanía agraria}

Así, se logró mantener la Comunidad Indígena y el uso exclusivo de las tierras por los mezcalenses. Pero desde entonces sólo una parte de los mezcalenses han sido responsables de su gestión y defensa y de elegir a las autoridades agrarias. Quizá por la división interna que conllevó, este cambio de reglas coincidió en el tiempo con la pérdida de control de la comunidad sobre la figura del delegado, que fue dejando de ser designado internamente para pasar a ser competencia del presidente electo de Poncitlán. Con ello también los Jueces de Barrio fueron perdiendo razón de ser.

Como en muchos lugares, las estructuras e instituciones comunitarias de Mezcala se fueron adaptando y pasaron a formar parte de todo el entramado institucional creado alrededor del PRI para manejar el poder. ${ }^{9}$ Las autoridades agrarias entraron a formar parte de esas

${ }^{9}$ El Representante de la Liga de Comunidades Agrarias del Estado firma el Acta Reconocimiento y Titulación de octubre de 1974; y al menos desde 1982 la Casa Comu- 
"instancias paralelas" al poder municipal que se basaba en la calidad de "sujeto colectivo de derecho agrario" de ejidos y comunidades con una autonomía que se manifestaba en el impuesto predial (Baitenmann 2001, 103-107). Esto hizo de su calidad ciudadana en una forma de "ciudadanía agraria": a través de la inserción en ese circuito de relaciones, instituciones, favores, etcétera que entran en las relaciones de poder -los cacicazgos regionales y estatales (Knight 2001) - y acaban creando unos deberes y unas obligaciones que se desprenden del hecho de ser "los hijos predilectos del régimen" (Warman 1972). En una situación en que la ciudadanía "formal", como mexicanos es bastante deficitaria en cuanto a contenidos reales, este "ser campesino" aportaba la posibilidad de obtener acceso, tanto a ciertos espacios de decisión y a satisfactores cotidianos, como conseguir servicios para la comunidad (Baitenmann 2007). Y en concreto, para mantener la integridad del territorio comunitario posiblemente de la única forma posible.

Desde esta inserción en la "cultura de Estado" agraria (Roth et al., 2004, 192), el ser “indígena” fue en Mezcala como en muchos otros lugares, una forma que tomó la ciudadanía agraria, una forma especial de ser campesino, que era equivalente a ser "comunero" y se encontraba en el mismo nivel que ser "ejidatario". Para las autoridades mexicanas, este término hacía referencia a una forma de poseer la tierra y por tanto de relacionarse con el Estado, la sociedad y el mercado desde ese uso exclusivo del territorio. Pero no hacía referencia necesariamente a un calidad étnica.

\section{UNA COMUNIDAD INDÍGENA DE JALISCO}

Toda esta inserción en la lógica agraria incidió en la recreación de la etnicidad, de los contenidos y formas del "ser indígena". Como dice Escalona $(2004,177)$ estas "redes institucionales" modelan las formas en que se vive y se reproduce la etnicidad - pero eso no significa que dejen de ser o que sean "menos indígenas"-. Y en el caso de

nal es un pequeño y deteriorado espacio que contrasta con el tamaño y ubicación de la Delegación. 
Mezcala lo hacen de una forma concreta: la de aquellas comunidades que no fueron consideradas "indígenas" en términos étnicos.

\section{Una identidad clara}

En Mezcala hace mucho tiempo que dejó de hablarse el nahua, no hay prendas o marcadores externos que sean considerados como indígenas, ni forma parte de una "región indígena" (Muñoz 2009b). ${ }^{10}$ Como muchas otras comunidades en el país, al no contar con éste u otros rasgos culturales que la "definan" o caractericen, no ha sido considerada étnicamente diferenciada y no fueron ni son sujetos de las políticas indigenistas del INI o ahora la CDI (Bastos 2010b). En este sentido, para el Estado mexicano, no son "indígenas", sujetos culturalmente diferenciados y socialmente "marginados" y por tanto no entraron en las redes institucionales que se definían desde una "ciudadanía étnica" menos desarrollada que la "agraria" pero también con sus propios satisfactores. ${ }^{11}$ Mezcala es un ejemplo de lo que Lameiras decía al referirse a "la persistencia multiforme de los grupos indígenas en una región que nunca había sido tocada por la política indigenista" (citado en De la Peña 2008, 57). ${ }^{12}$

Pero los mezcalenses no distinguen. Hasta donde yo he podido observar y otros autores corroboran (Hernandez 2000; Castillero 2006; Cárdenas 2006; Alonso 2008), los mezcalenses en general no dudan en autoidentificarse como indígenas. Quizá no es una identidad central en muchos de sus comportamientos sociales, pero al mismo tiempo, es una identidad asumida abiertamente y con orgullo (Bastos 2010a, 2010b). La identidad local se basa en una relación privilegiada con el territorio y la historia (Castillero 2006;

\footnotetext{
${ }^{10}$ En Mezcala sólo se considera a los habitantes del vecino pueblo de San Pedro Itzican como "indígenas", pero apenas les incluyen en sus planteamientos identitarios.

${ }^{11}$ Evidentemente acá estoy usando el término "ciudadanía étnica" sin los contenidos que le han otorgado diversos estudiosos (véase Leyva 2007). Me estoy refiriendo a la forma en que el Estado les interpela por el hecho de ser indígenas, las redes e instituciones a través de los que lo hace y los derechos y obligaciones que ello conlleva.

${ }^{12} \mathrm{El}$ indigenismo en Jalisco se formó prácticamente sólo alrededor de los huicholes y a partir los ochenta también atendió a los nahuas del sur del Estado (De la Peña 2002; Arévalo 2007).
} 
Moreno 2008; Alonso 2008) un "estar aquí desde siempre" (Bastos 2010a). Y se consideran indígenas como una consecuencia de esta relación con el territorio, - “ya estábamos cuando llegaron los espańoles" - y la propiedad comunal actual es la muestra más evidente de su calidad étnica. Al estar asociada a esta tierra otorgada - primero por el rey y después por el presidente- se vive dentro de un genérico "indios mexicanos" que es una forma de insertarse en la nación (Warman 2003a).

Por su aparición ubicua en el episodio de la defensa de la isla, el término "indio" contiene una importante carga de orgullo, que se vincula con "los antepasados", pero no excluye la conciencia de una relación de subordinación y exclusión, que se explicita en una relación con Poncitlán que responde muy bien a la idea del "proceso dominical” (Aguirre Beltrán 1991), y renovada en los momentos en que sus vecinos les recuerdan que son "indios" de formas diferentes.

\section{La institucionalidad indigena}

Estamos entonces ante un tipo de vivencia de la etnicidad que no se basa tanto en la diferencia cultural como en la continuidad histórica y la tenencia de la tierra, y en la que no ha incidido apenas el indigenismo con sus programas "culturales". Es similar a la reportada en las comunidades nahuas del sur de Jalisco (Lameiras 1990; De la Peña 2006; Lucio et al., 2008), y también las del Ajusco en el Distrito Federal (Medina 2005 y coord. 2007; Sánchez y Martínez 2008). En estas últimas, Medina plantea tres pilares institucionales para la recreación étnica, cuya situación en Mezcala muestra su raigambre en este tipo de colectividades, pero también la situación actual. La primera es la institucionalidad administrativa, que dejó de estar en manos de la comunidad desde que el delegado es elegido por el presidente municipal de Poncitlán, normalmente entre los cuadros locales de su partido.

La segunda, la institucionalidad religiosa muestra situación interesante. Por un lado, no existe una "carrera" ni un entramado institucional que recuerde de alguna manera al "sistema de cargos" del Ajusco, por ejemplo (Medina 2005), ni ejerza visiblemente como esa 
"tercera pata" de la comunidad. Pero al mismo tiempo, las actividades religiosas y festivas han creado una red de una densidad de una profundidad y una vitalidad impresionantes a través de un apretado calendario -Moreno (2008) identifica 24 fiestas en el año- en que los y las mezcalenses participan a través de "representaciones" como la "Judea en Vivo" o las "Pastorelas", los numerosos grupos de diferentes tipos de danzas -Tlahualiles, Huehuenches, de la Conquista, Pacaqueros, Viejitos- que congregan generaciones y orígenes diversos en momentos festivos como las Cruces del 3 de Mayo y el día de Guadalupe. También se participa a través de los "cargos" que vinculan a compadres, amigos vecinos y familiares alrededor de los gastos festivos. Podemos hablar entonces de un entramado social que muestra y en el que se recrea una identidad - "identidad danzante" como la descrita por Lameiras (1990) - y un sentido de pertenencia evidentes, pero sin un asidero organizativo claro.

En este contexto, la "tercera pata", la institucionalidad agraria ha sido, en las últimas décadas la depositaria de la titularidad de la comunidad: los comuneros han sido los encargados de la interlocución con el Estado, de la que ha dependido buena parte de la calidad de indígenas. Ha conseguido cumplir su papel de haber sido "los guardianes del territorio" en medio de un entramado político cambiante y una pérdida progresiva de membresía. Pero los comuneros fueron envejeciendo y no nombraron herederos, pues pensaban que los jóvenes iban a acabar vendiendo las tierras.

\section{Mezcala ante el Estado neOliberal y la globalización}

Con el cambio de siglo, fueron llegando a Mezcala los efectos de las transformaciones que venían gestándose en el mundo y en el Estado mexicano en los últimos tiempos. En las últimas décadas, la población y el territorio de Mezcala han ido entrando en las dinámicas de la globalización a través de formas muy variadas.

Por un lado, los mezcalenses fueron saliendo a Estados Unidos como tantos otros lugares del occidente de México a partir del Programa Bracero en los años cuarenta del siglo xx y desde entonces no han parado. Las huellas de "El Norte" están presentes en todas par- 
tes más allá de la dependencia de las remesas: la obras que el Club Mezcala; la presencia de "los Hermanos Ausentes" en la Feria Titular en agosto; los jóvenes con la indumentaria popular latina organizados en "gangas". Esta relación con los Estados Unidos es la muestra más evidente del proceso de dispersión poblacional que se ha dado en Mezcala, que llega a ciudades de la frontera norte, pero sobre todo a Guadalajara y todo el corredor de El Salto.

La cercanía con Guadalajara promueve otro proceso que tiene que ver con la relativización de las fronteras entre lo urbano y lo rural (Arias 2009), que se aprecia en procesos como la combinación residencial entre el pueblo y el área metropolitana, el complemento de la actividad agrícola con los empleos urbanos, la dedicación de parte del suelo a actividades periurbanas, el empleo de jóvenes mezcalenses en las maquilas de Guadalajara, etcétera.

\section{Presión inmobiliaria y nuevo modelo económico}

La dinámica de urbanización de localidades rurales periféricas afecta a Mezcala de forma especial, pues se combina con la presión del capital inmobiliario de la ribera de Chapala, que ya no ha dejado prácticamente espacio en la zona noroccidental. ${ }^{13} \mathrm{~A}$ través de esta presión, los mezcalenses se vinculan al turismo, que empieza a estar presente en el paisaje cotidiano del pueblo a través de algunos negocios, los paseos a la isla, y los carteles cada vez más presentes de propaganda institucional. Y sobre todo, está presente en combinación con una nueva ola de presión sobre el territorio comunitario con fines inmobiliarios.

Esta ola comenzó en 1999 con la "invasión” del Cerro del Pandillo por Guillermo Ibarra, un empresario tapatío. Bajo excusa de un programa de reforestación y usando un "prestanombres" local, construyó una mansión en pleno territorio comunitario. Casi al mismo tiempo en que la comunidad reaccionaba y emprendía un juicio

\footnotetext{
${ }^{13}$ En el área entre los poblados de Chapala y Jocotepec, sobre todo alrededor de Ajijic, se ha instalado desde mediados del siglo xx una importante colonia de jubilados norteamericanos, que llega a saturar totalmente el espacio disponible.
} 
agrario contra el invasor, en 2002, se inauguraba la carretera que unía la comunidad con Chapala y había sido postergada por más de 50 ańos. En vez de seguir el camino de terracería existente, se abrió a media altura del cerro, para lograr una "carretera panorámica” con vista al lago. En 2005, "llegó PROCEDE”, como recuerdan los comuneros, y en Asamblea se decidió que no se aceptaría firmar la desincorporación de las tierras. ${ }^{14}$

Pese a ello, el Plan de Ordenamiento Territorial para Mezcala que preparó la Presidencia de Poncitlán sí incluía partes del territorio dedicadas a "zonas turístico-hoteleras de densidad media" y otras con el eufemismo de "zonas habitacionales de densidad media" (Gobierno Municipal de Poncitlán 2006) y empezaron las obras de acondicionamiento del malecón -que nunca se terminaron por una "desviación" de los fondos-.

Ante esto, se fue generando una sensación de acoso entre los comuneros y demás mezcalenses, que se pude resumir en una de las frases más escuchadas: "No queremos acabar como los de Ajijic, sin tierras y trabajando para los extranjeros y tapatíos", y que se materializó en respuestas colectivas concretas, como la que cuenta un comunero:

estaban circulando varias hectáreas en la parte de El Comal. El [Presidente] de Bienes Comunales y los comuneros y población en general de Mezcala, nomás nos fuimos todos a cortar los alambres con los que habían cercado nuestras tierras. Querían fraccionar El Comal [...] fueron varios días los que se fue para limpiar todo. Ya nomás les dejamos todos sus alambres y postes, pá que no digan que estábamos robando.

${ }^{14}$ Dado que Mezcala es "comunidad indígena” y no "ejido", el programa no fue PROCEDE - Programa de Certificación de Derechos Ejidales-sino prodecom -Programa de Certificación de Derechos Comunales-. En este momento Mezcala es la única comunidad agraria de la ribera de Chapala y el municipio de Poncitlán que no entró al Programa. Vecinos como San Juan Tecomatlán, Tlachichilco o San Pedro Itzicán sí lo hicieron, y normalmente al principio del proceso, en los noventa. La tardía llegada de "los del PROCEDE" a Mezcala podría responder, según Jorge Uzeta (comunicación personal) a "una estrategia regional de las propias instituciones agrarias: solucionar primero los casos ejidales y comunales no conflictivos dejando los complicados al final". 
Todos estos hechos parecen mostrar el destino asignado por las diferentes esferas de gobierno a esta localidad como parte de la Ribera de Chapala. Mezcala ha dejado de ser para el Estado una comunidad campesina y se va convirtiendo en un espacio que debe insertarse a la economía del turismo que domina la región, como proveedora de servicios y espacio de construcción.

El desmontaje del Estado corporativo agrarista abre nuevas "oportunidades" de inserción económica para las comunidades antes agrarias, una nueva relación que se buscó cristalizar a través del PROCEDE y PRODECOM. Se pretendía que ya no fueran un sector bajo especial protección del aparato estatal, sino unos ciudadanos que se insertaran al mercado como propietarios de unas tierras que pueden ser mejor trabajadas por otros que a su vez empujarían a una inserción más competitiva de México en la economía global (Zendejas y De Vries, eds., 1995; Warman 2003b; De Ita 2003). A partir de ese momento, se han ido desmontando las estructuras del Estado posrevolucionario, de formas abiertas - como la supresión de la SRA- o más implícitas como el apoyo cada vez menor a los reclamos agrarios por parte de las autoridades de los tres niveles en todas partes. En Mezcala, este desmontaje del Estado agrarista ha ido de la mano de las políticas estatales y municipales para promocionar las actividades turísticas e inmobiliarias, que han provocado la reacción de los mezcalenses organizados.

\section{La reconstrucción de la isla}

El evento que más claramente ha mostrado esta intención de convertir a Mezcala en un destino turístico abierto al mercado inmobiliario ha sido la restauración de los edificios de la isla, que se iniciaron en 2006 a raíz del Bicentenario que entonces se acercaba. Tras unos estudios arqueológicos e históricos, en 2007, empezaron las obras físicas llevadas por un equipo que el INAH avalaba y daba el soporte técnico, la Secretaría de Cultura aportaba el financiamiento y la Presidencia Municipal de Poncitlán ejecutaba la obra. A partir de ese momento, las obras han ido avanzando a golpe de presupuesto y temporadas secas; pero con la oposición creciente de unos comuneros renovados y activos. 
Desde que empezó este proceso, la Asamblea de Comuneros se quejó de que no se le estaba teniendo en cuenta como autoridad responsable de un territorio que es parte de la propiedad comunal. Conforme avanzaba el proceso, fueron denunciando que la forma en que se estaban llevando a cabo las obras demostraba poco respeto por la historia de los insurgentes de Mezcala y por los restos que pudieran haber en un lugar como la isla. ${ }^{15} \mathrm{El}$ hecho de que se reconstruyera el presidio construido después de la defensa, muestra claramente para los comuneros que el objetivo de toda la obra no es exaltar aquel episodio histórico en el contexto del Bicentenario, sino activar una atracción turística que refuerce el papel de Mezcala en la zona. $Y$ ante esto, denuncian ese modelo de turismo en el que de nuevo se repite la inserción que como pueblos indígenas, les han obligado durante siglos. ${ }^{16}$ En la tónica de desconocimiento de la legitimidad agraria que se mencionaba, estas instancias siempre han dicho que los comuneros "son sólo un grupo" de Mezcala, negándoles el carácter de autoridad desde el que ellos hablan. ${ }^{17}$

\section{LA RECREACIÓN COMUNITARIA COMO PUEBLO COCA}

Esta forma de enfrentarse y argumentar contra estas políticas estatales que afectan al territorio de Mezcala se entiende si sabemos que se han dado en forma paralela y han reforzado todo un proceso de renovación interna que se ha viendo dando en la comunidad indígena de Mezcala, que se puede entender como el proceso de recreación y adaptación de la lógica comunitaria al contexto global neoliberal multicultural.

\footnotetext{
${ }^{15} \mathrm{El}$ arquitecto Cuauhtemoc del Regil, del INAH, ha denunciado repetidamente cómo las obras destruyeron evidencia arqueológica muy importante, además de estructuras construidas durante el cerco de 1812-1816 (véase, por ejemplo, la extensa entrevista en La Jornada Jalisco, sábado 17 de noviembre de 2007).

${ }^{16}$ Todas estas razones se han desarrollado en múltiples escritos internos, públicos, comunicados, prensa, etcétera.

${ }^{17}$ Todo este pleito ha vuelto a colocar a la isla en el centro de la construcción de la identidad mezcalense, dotándola de unos contenidos nuevos acordes al contexto político en que se da (Muñoz y Bastos 2010).
} 


\section{El Colectivo y los comuneros}

Cuando los fenómenos que estamos viendo empezaron a mostrarse como amenazas evidentes a la integridad territorial que había sido la razón de ser de la Comunidad Indígena, los comuneros vieron la necesidad de renovarse institucional y generacionalmente. Para ello se aliaron un grupo de jóvenes mezcalenses que desde inicios de siglo venían trabajando como "Colectivo Mezcala" alrededor de todo lo que supuso la "6a Declaración de la Selva Lacandona” y más tarde "La Otra Campaña”. Desde estos espacios y basándose en la evidencia etnohistórica (Baus 1982), este Colectivo desarrolló la propuesta de Mezcala como una comunidad perteneciente al "pueblo coca" (Moreno 2008; Jacobo y Godoy 2006). Cuando se planteó en Jalisco la aprobación de una Ley Indígena Estatal que servía de soporte a la Ley planteada por Fox en 2001 (Hernández 2004), Mezcala no fue considerada como "pueblo indígena" de Jalisco, y se reforzó la alianza con los sectores que se habían negado a dar por buena esta ley. ${ }^{18}$

Es paradójico que la propuesta estatal de ley indígena de Jalisco niegue a los coca de Mezcala como pueblo indígena por "no cumplir" los "requisitos" que el actual gobierno pretende imponer para certificarlos, cuando que el mismo gobierno es el culpable de su erosión cultural. Su no reconocimiento es otro ataque a los pueblos (Los coca de Mezcala siguen vivos, 2006).

Tras el paso de la caravana de "La Otra Campaña” por el cercano municipio de El Salto y la participación en actividades del Congreso Nacional Indígena -CNI-, el Colectivo logró que se realizara en Mezcala en noviembre de 2006 el "Foro Nacional de Defensa de la Madre Tierra y la Autonomía Indígena”, que convocó a representantes de grupos variados y contó con la presencia de dos comandantas del EZLN expresamente llegadas de Chiapas. Fue el Comisariado el que organizó la actividad. Se reforzó la vinculación

${ }^{18}$ Siguiendo la lógica del periodo indigenista, los "pueblos indígenas" de Jalisco son, según la Ley Indígena, el Pueblo Wixaritari y el Pueblo Nahua, además de los miembros de migrantes en las ciudades (Ley sobre los Derechos y el Desarrollo de los Pueblos y las Comunidades Indígenas del Estado de Jalisco, 2006) 
con los jóvenes del Colectivo, y les sirvió para conocer comunidades que, en situaciones similares, habían procedido a una transformación de sus estructuras.

Así empezó el proceso de renovación interna de la Comunidad, que movilizó a más de 200 personas semanalmente durante más de dos años, y se ralentizó tras agosto de 2008, cuando entró en una fase de conflicto que se verá después. Los ejes de este proceso han sido las actividades de ampliación de la base social, la redacción de un Estatuto Comunitario y la renovación de la defensa del territorio desde nuevos foros y espacios. ${ }^{19}$

\section{La renovación del censo}

Cuando empezó esta dinámica, sólo quedaban ochenta comuneros vivos, de los que la mitad hacía mucho que no residían en el pueblo ni participaban en las actvidades. Como consecuencia, como mucho cuarenta comuneros acudían regularmente a las asambleas y actividades del Comisariado. Esto no sólo implicaba una merma en la representatividad, sino una seria dificultad para la capacidad de un trabajo que, sin embargo, llevaban con entereza. Por ello, la misma Comunidad buscó cubrir la brecha generacional abierta y aprovechar para ampliar la pertenencia más allá de sus miembros originales y sucesores y así subsanar la situación creada con el Censo Básico.

La renovación del censo se hizo a través de "juicios de herencia" para incorporar a los descendientes de 406 censados originarios. Al mismo tiempo, se abrió un proceso de "ampliación" a gente que quisiera pertenecer a la Comunidad. Aunque las dificultades legales no han permitido aun completar estos procesos, desde 2007 los "nuevos comuneros" son un grupo de unas cien personas que realizan diversas actividades en la Comunidad y una parte acude regularmente a las Asambleas, aunque no tengan aún derecho a voto.

Esto ha implicado algo más que un relevo generacional, pues los hombres y mujeres que se han sumado a las actividades de la Comu-

${ }^{19}$ El Estatuto se trabajó durante 2007 y 2008, y finalmente fue aprobado por la Asamblea en junio de 2009 y ratificado por el Tribunal Agrario posteriormente. 
nidad suponen una diversificación de la gama de ocupaciones y actividades de los comuneros, que supera con mucha la concepción de la comunidad sólo como "agraria”. Algunos de los jóvenes estudiantes y profesionistas, los albañiles, obreros y técnicos diversos, los migrantes y lancheros mantienen una actividad campesina al cultivar chayote u otros productos, pero no viven de eso, y han ampliado con ello los temas de preocupación de la Asamblea. Lo mismo ocurre con las opciones ideológicas: si en el pasado la pertenencia al partido oficial era la única forma de participación política; en la actualidad los miembros de la comunidad responden a la variedad de partidos y opciones presentes en Jalisco - desde el PAN al zapatismo, pasando por el PRI, PVEM O PRD- que ha sido resuelta con el acuerdo de dejarla fuera de las actividades de la Comunidad. ${ }^{20}$

Esta ampliación generacional ha sido habitual en diversos momentos en las comunidades agrarias del país (Dietz 1999; Martin 2002; Bofill 2002; Gil 2006; Garibay 2002;)y es un primer paso hacia una nueva comprensión de la idea de la Comunidad, que de lo agrario -es decir, formada por los propietarios de la tierra- lleva a lo indígena, todos los integrantes del núcleo histórico que es Mezcala. La transición es lenta-la mayoría de los "nuevos comuneros" pertenece a familias de comuneros censados- porque la dependencia de la legitimidad agraria y los sentidos de pertenencia que otorga son fuertes, pero incluso en el Estatuto aparece ya esta concepción más amplia: ${ }^{21}$

ARTICULO 13.- La Asamblea General se integra para efectos agrarios con la participación de todos los comuneros en pleno goce y ejercicio de sus derechos, y para las demás cuestiones en general por aquellos originarios legíti-

${ }^{20}$ Es cierto que a diferencia de lo que es normal en esta comunidades agrarias (Muñoz 2009a, por ejemplo), en las Asambleas de Mezcala se junta gente que por fuera realiza actividades partidistas -como se vio claramente en la campańa electoral de mediados de 2009- pero que en su interior no lo manifiesta y trabaja conjuntamente; y que las divisiones internas que pueda haber entre comuneros $-\mathrm{o}$ con otros sectores locales- no corresponden con las de los partidos.

${ }^{21}$ De una forma aun tímida se hace frente a la dispersión espacial de la comunidad mezcalteca. No se puede hablar de una renovación institucional al estilo de las "comunidades transnacionales" (Besserer 2002; Gil 2006), pero se reconoce institucionalmente al Club Mezcala y la dificultad de cumplir los requisitos por la residencia fuera del pueblo. 
mos de la Comunidad Indígena de Mezcala, que respeten los principios de este estatuto (Estatuto..., 2008, 8).

\section{El Estatuto y la nueva forma de ser indígena}

El nuevo Estatuto es la columna vertebral de la reconstitución comunitaria alrededor de la Asamblea de Comuneros, y pretende superar lo agrario para convertirse en la "constitución" que rija la ciudadanía comunitaria de los mezcalenses como parte del "Pueblo Coca de Mezcala" que renueva su "Gobierno Tradicional" para mantener su autonomía.

Por ello es la mejor muestra de la nueva propuesta de comunidad que ya no se entiende como una instancia agraria de unos "indígenas mexicanos", sino como parte de un Pueblo Indígena con derechos históricos sobre el territorio.

Ante la negativa de reconocimiento oficial y con la inserción en las redes zapatistas, se refuerzan las argumentaciones sobre su uso ancestral -tan presente en la lógica local mezcalteca- que conllevan a un ejercicio del autogobierno y la búsqueda de la autonomía como pueblo originario. Con ello, el ser indígenas se entiende de una forma nueva, acorde con las propuestas desarrolladas en las últimas décadas por el movimiento indígena en América Latina (Bengoa 2000; Sieder 2002; Leyva et al., 2008).

De hecho, el estatuto reclama su legitimidad de tres fuentes. La primera es el Título Primordial, del que el presente Estatuto se considera sólo una actualización. ${ }^{22}$ La segunda es la legislación mexicana, con la Constitución y las leyes agrarias, que los neozapatistas reivindican como parte de la herencia revolucionaria. ${ }^{23} \mathrm{Y}$ por fin, el Convenio 169 de la oIT otorga la legitimidad internacional que permite hablar como Pueblo Indígena y reclamar el derecho al uso autónomo del territorio.

${ }^{22}$ En palabras de don Agapo, comunero censado: "Nuestra arma es el Título Virreinal, que ahora es el Estatuto. Nos lo dieron los antepasados en 1534 y ahora es de todo el pueblo".

${ }^{23}$ Esta dimensión nacional mantiene a los cocas dentro de la idea de unos indígenas mexicanos que tiene derechos ciudadanos como tales. 
Esta renovación de las bases ideológicas de la comunidad se manifiesta en la formulación de la idea de un "Gobierno Tradicional de la Comunidad" cuyo núcleo son las instituciones agrarias -Asamblea General de Comuneros, Comisariado de Bienes Comunales, Consejo de Vigilancia- pero que incluye otras instancias comunitarias existentes -Jueces de Barrio y Delegado Municipal-y otras nuevas -Consejo de Primeros Comuneros, Comisión de Seguridad Comunal, Capitanía de Puerto de la Comunidad de Mezcala y Comisión de Transparencia y Presentación-. Según el Estatuto, son aquellos "órganos y autoridades", que "de acuerdo a los usos y costumbre propios integran el Gobierno Tradicional de la Comunidad" (Estatuto 2008, 7).

Así, a partir de las estructuras vigentes, se busca ampliar las bases de representación y gobierno a partir de una nueva legitimidad manifestada en los términos como "gobierno tradicional" y "usos y costumbres", que suponen nuevas formas de entender y nombrar la realidad comunal. Su existencia es la que da derecho al autogobierno y capacidad de decisión sobre su territorio -y la isla en concreto- según las nuevas formas de entender los derechos de los pueblos indígenas. Esta formulación aparece en los textos y comunicados desde los que la Comunidad Indígena de Mezcala ha dado a conocer sus reclamos.

Como el Estatuto surge en un contexto concreto de defensa de la integridad territorial, bastantes de sus artículos se dedican a la defensa de esta integridad por diversas vías:

ARTí́culo 148.- Las tierras de la Comunidad gozan de la protección especial que les otorgan la Constitución Mexicana y el Convenio Ciento Sesenta y Nueve de la Organización Internacional del Trabajo "Sobre pueblos indígenas y tribales en países independientes" así como la Ley Agraria [...] No podrán existir enajenaciones, fideicomisos, concesiones, embargos, despojos, etc. dentro del territorio de la comunidad" (ibid. 36). ARTículo 161.- Cualquier persona ajena a la comunidad que pretenda poseer terrenos de la comunidad se le reconocerá como invasor (ibid. 39). ARTí́culo 183.- La isla, por su importancia, pues es el corazón del territorio de nuestra comunidad, seguirá siendo custodiada por la misma comunidad, por lo que nadie puede crear posesiones (ibid. 43). 


\section{La defensa territorial y los conflictos internos}

La defensa del territorio ha sido uno de los ejes básicos del proceso de renovación comunitaria: los reclamos han mantenido el espíritu de lucha entre los comuneros - censados y nuevos-, las actividades han puesto la base de la renovación de la pertenencia comunitaria, y los argumentos han sido expuesto en foros y actividades. Los enfrentamientos con el INAH, la Secretaría de Cultura y la Municipalidad de Poncitlán por la isla son los que han sido más conocidos y han generado más dinámicas internas y externas. Ante esta nueva amenaza al territorio, se reforzó el papel del Comisariado de Bienes Comunales, como núcleo desde el que se ha venido haciendo una oposición a unas obras que se convirtieron en una cuestión política de alcance estatal y federal de mano de las diferentes redes con las que se relaciona el Colectivo y ahora la Comunidad: no sólo el CNI, sino los Afectados Ambientales, los colectivos anarcopunks, los espacios académicos.

En estos espacios y en las actividades locales, el discurso como Pueblo Indígena se utiliza para reforzar los argumentos históricos sobre los que está construida la identidad mezcalense (Bastos 2010a), que toma así una nueva dimensión más allá de lo local y en que empiezan a aparecer elementos relacionados con "la cultura". ${ }^{24}$

La comunidad de Mezcala, en la ribera del lago de Chapala, es un bastión de resistencia indígena que tuvo su momento cumbre en lucha por la independencia de México al defender su isla contra el Ejército Realista (Los coca de Mezcala siguen vivos, 2006)

¿Por qué lucharon los insurgentes? Lucharon por el respeto a nuestras tierras, gobierno y cultura, buscaban la libertad para el pueblo (El pueblo coca de Mezcala. Una historia de lucha, 2008)

${ }^{24}$ La historia suele ser un elemento importante de justificación de las demandas y discursos, y más en espacios indígenas; dando lugar a la construcción de versiones enfrentadas e incluso contradictorias (Velásquez 2004; Gómez Carpinteiro 2004), pero en Mezcala juega un papel importante en la identidad local -posiblemente ante la ausencia de otros elementos distintivos- (Bastos 2010b) y además es una base importante de una memoria local que da mucha importancia a las fuentes escritas (Muńoz 2009). 
Nuestra historia, nuestros abuelos nos han enseñado a defender lo nuestro, así que de la misma manera que ellos empezaron a anunciar su gran proyecto de turismo para el rico sobre el pobre, sobre nuestro pueblo y su historia, nosotros presentamos el sentir de nuestra comunidad (Declaratoria de Mezcala, 2008) .

Además de transformar la forma de entenderse étnicamente, la lucha por la integridad del territorio comunitario llevó a los comuneros a enfrentarse a intereses concretos. No sólo al proyecto de inserción económica que defendía la Presidencia Municipal de Poncitlán, sino a intereses particulares como el de Ibarra y los de los de los mezcalenses insertos en procesos de privatización de hecho. Todo esto suponía un nuevo proyecto de comunidad, diferente en parte al que se puso en marcha a mediados del siglo xx. De nuevo, como medio siglo antes, dos versiones estaban en pugna.

Por ello, todo se paralizó tras las elecciones para autoridades comunitarias de agosto de 2008, en que venció una planilla compuesta por gente que no había participado en el proceso previo y que apenas conocía la mecánica del Comisariado. A finales de ese año, los comuneros se quejaron de que los procesos judiciales de renovación y de recuperación de las tierras no avanzaban, que las autoridades no convocaban a la Asamblea y en cambio negociaban con la municipalidad sobre el futuro de las obras de la isla. Asumiendo entonces que trabajan para defender intereses ajenos a la comunidad, en marzo de 2009, la Asamblea les desconoció, pero ellos siguieron con el apoyo de la municipalidad de Poncitlán. Comenzó una época de "doble directiva" en que ambas decían manejar la legitimidad y legalidad: las autoridades depuestas, las que provenían de la municipalidad; y las recién electas, de las instancias agrarias y de la Asamblea comunitaria-elemento clave en la dinámica local-.

En octubre de 2009 se produjo un allanamiento de la Casa Comunal por parte de la directiva depuesta, acompańada de Ibarra y protegidos por la policía municipal, a lo que siguió un plantón por parte de los comuneros que duró un mes y sirvió para reforzar su posición entre los mezcalenses. Esta demostración de fuerza sirvió para terminar con la alianza entre el INAH y la SCJ con la municipalidad de 
Poncitlán, pues el recién elegido presidente municipal decidió dejar la táctica de su predecesor y desde antes de tomar posesión inició un acercamiento con los comuneros que para mediados de 2010 se manifiesta en una serie de obras y proyectos conjuntos y en un acuerdo sobre el manejo de la isla y las obras al que se sumó también la SCJ.

\section{MEZCALA: CONTINUIDAD HISTÓRICA, RENOVACIÓN Y COMUNALISMO}

Mezcala, como otras comunidades indígenas, se halla en un momento de renovación y para ello apela a su profunda base histórica vista desde nuevas perspectivas. Este proyecto no sería posible sin la existencia de una serie de prácticas y comportamientos que son los que nos permiten hablar de Mezcala como una comunidad. La identidad local compartida y su raigambre en el territorio; la organización local con base en barrios; las prácticas sociales como las danzas y fiestas y otros rituales en que todo el pueblo se suma; las instituciones agrarias. Todas ellas serían las muestras del "comportamiento comunitario" (Zárate 2004, 63) que se ha ido formando en el tiempo y cuyas estructuras actuales vienen del agrarismo posrevolucionario sin indigenismo, en un contexto de dispersión, metropolización y diversificación.

\section{La recomunalización}

Estamos pues ante un espacio social que podemos considerar como una comunidad por su historia e institucionalidad local, pero que lejos de responder a la imagen de una localidad rural, aislada o "tradicional", está totalmente cruzada por dinámicas propias de la globalización -la migración, las políticas neoliberales, el turismo, la metropolización, la revitalización étnica- que impulsan hacia una renovación como comunidad, más que a su desaparición.

Para entender este momento y las dinámicas que se dan en él, es útil la diferenciación entre los comportamientos comunitarios, como "prácticas culturales conformadas históricamente" y el "comunalismo como ideología [que] exalta el ideal de la comunidad y 
la vida comunitaria" y puede convertirse en el motor que mantenga vivos de hecho esos comportamientos históricamente creados, renovándolos de acuerdo al nuevo contexto (Zárate 2005, 63-65).

Lo que está ocurriendo en Mezcala se puede entender como "recomunalización”. Más allá de una dicotomía entre la desaparición y el "regreso" a una situación ideal que a saber si existió, se trata de un proceso por el cual se está renovando y a la vez transformando la calidad comunitaria de los comportamientos sociales de los mezcalenses. A pesar de los presagios de los mayores más catastrofistas sobre los efectos de la migración o la salarización en la ciudad en "las costumbres", la participación masiva en los rituales y danzas -con una gran presencia de jóvenes-, la renovación institucional y la participación de los migrantes muestran una vitalidad comunal renovada. Pero el futuro no va a ser algo parecido a lo que hubo, sino un tipo de comportamiento social adaptado al contexto de globalización -turismo, migración, derechos indígenas-y políticas neoliberales.

Pero ahora, para que la comunidad se pueda seguir manteniendo, es necesario "reimaginar la comunidad” (Velásquez 2004, 221), una renovación de lo que significa ser mezcalense, actualizar los contenidos históricos sin perder su capacidad de identificación.

\section{El comunalismo como pueblo indigena}

Para que este tipo de procesos sea exitoso, depende al menos de dos procesos (Zárate 2004, 71). Uno es el establecimiento de una versión de la comunidad, un discurso que logre consenso entre los diferentes sectores que la forman. Acá es donde entra el "comunalismo" como discurso. Cuando las instituciones y la legitimidad del Estado corporativo se derrumban y ser una comunidad indígena en términos agrarios ya no es garantía para mantener la integridad del territorio-como lo fue en las cinco últimas décadas para los mezcalenses-, empieza a ser más útil ser considerado como indígena desde la figura de "pueblo" y todo lo que ello conlleva.

El discurso asociado al pueblo coca propone una lectura del recorrido histórico de la comunidad desde unos orígenes ancestrales que hasta ahora no tenían importancia, pero que enlaza con la legi- 
timidad internacional de los derechos indígenas. Pero no es un reflejo o simple aprovechamiento de la multiculturización del discurso neoliberal, que pretende convertir a los indígenas y "lo indígena" en un nuevo tipo de ciudadanos culturalmente definidos, una nueva mercancía global y una nueva forma de relación que no cuestiona las estructuras heredadas ni las actuales (Díaz Polanco 2006; Hale 2007; Bastos 2007).

Frente a la propuesta multicultural, se opone el paradigma autonómico (Burguete 2010) Las propuestas como la de Mezcala toman la legitimidad de ese discurso y le dan al término "derechos indígenas" el contenido que ellos consideran que debe tener -no el que da el Estado-. Los términos de "autonomía" y "autodeterminación" dejan de ser declaraciones vacías para tomar sentido en el accionar y la recreación de la comunidad. Con ello se está dando una reinvención de la comunidad como forma de insertarse en la globalización. En palabras de Roth et al. $(2004,208)$, cuando "se eliminaron las garantías del Estado para la continuidad de las comunidades y los comuneros", se retomó el discurso étnico que se había ido construyendo a otro nivel. Con ello se fue eliminando "la separación cultural entre comunalismo popular y la etnicidad" que dejó de ser un recurso en la "cultura de Estado". ${ }^{25}$

Esta renovación del discurso es vista por los comuneros como un paso más dentro de una forma histórica de mantener el control sobre el territorio: el Titulo Primordial supuso aceptar las reglas de la Colonia -que el rey les había "otorgado" algo que ya era suyo-; la defensa de la isla se hizo para mantener ese control -y sirvió para renovarlo por lo menos un siglo más-. Después de la Revolución, fue necesario solicitar el "reconocimiento presidencial", asumirse como parte de los "hijos predilectos" (Warman 1972), diluyéndose, a cambio, parte de su ser indígena. Pero si ahora el Estado exagrarista ya no es capaz de asegurar el control sobre el territorio, quizá haya que buscar la seguridad en la legitimidad como pueblo indígena.

${ }^{25} \mathrm{Al}$ utilizar el discurso étnico desde este "comunalismo popular", se crea de hecho una alternativa a las políticas oficiales de la diversidad (Hernandez et al. 2004), que "no reconocen este espacio" (Roth 2004, 208) de forma legal como sujeto de derecho. 
Esto implicaría la novedad de que la seguridad del territorio ya no se busca a través de una "concesión" del Estado, sino reclamándole que cambie su actuar en relación con ellos Por ejemplo, reconociéndole como indígena como no se ha hecho antes y aunque no se cumplan los "requisitos culturales" e institucionales. De ahí lo novedoso de la propuesta del pueblo coca: no hay antecedentes de relación con el Estado desde esa etiqueta, no está "contaminada", no forma parte de la "cultura de Estado" de los jaliscienses.

El reto es lograr que la identidad como pueblo coca sea asumida por los mezcalenses como propia y garantice la cohesión alrededor de la idea de la comunidad como espacio social legítimo. Pero lo que les llama la atención y les cuesta incorporar a los mezcalenses es la calidad de "pueblo" y el apelativo de "cocas", que es precisamente donde se manifiestan los elementos que podríamos considerar más novedosos: el reclamo de ancestralidad como pueblos originarios y la cultura como elemento identificador.

Sin embargo, la versión zapatista en boga en Mezcala pone el énfasis en la autonomía y oposición al Estado, y no tanto en los derechos culturales. Por su origen de izquierda, se relaciona el ser indígena con el ser pobre y con el despojo histórico, que se actualizan en el contexto de globalización neoliberal. Los términos de resistencia al poder en que se plantean, de una forma muy unida al "ser mexicano", hacen que esta versión suene conocida para los mezcalenses por su pasado agrarista. Y tampoco les suena mal el reclamo a una "autonomía" que vienen reclamando históricamente al Municipio de Poncitlán. De esta forma, los contenidos de la nueva propuesta van pasando "selectivamente” (Nugent y Alonso 2002) a la identidad mezcalense.

\section{Las bases materiales de la renovación}

Pero además, para que el proceso de recomunalización avance en el sentido deseado por sus promotores, debe mostrar su funcionalidad. En Mezcala no hay un recurso económico como el forestal que el Comisariado pueda manejar y ser la razón de ser de esa renovación y sobre todo, de la legitimidad local de la estructura agraria (Garibay 2008; Bofill 2002). Hay en marcha planes de cooperativas, de em- 
presas comunitarias ligadas a la nueva Comunidad, pero hace falta que los comuneros convenzan al resto de sus vecinos de la utilidad y conveniencia de mantener el carácter común y excluyente de su territorio. Es necesario demostrar que en estos momentos de globalización, la tenencia comunitaria de la tierra puede ser más útil y beneficiosa que la entrada a ese "progreso" que propone el Estado, y que en este caso está asociado directamente a la gestión del turismo. Por eso, la nueva "batalla por la isla", es crucial, pues en ella se va a dirimir la posibilidad de una gestión comunitaria ajena a los cánones neoliberales que maneja el INAH.

La apuesta que está detrás es lo que Garibay $(2008,16)$ llama "la revolución comunalista”: mostrar que la tenencia comunitaria puede aportar una base para que todos los mezcalenses mejoren sus condiciones de vida aprovechando comunitariamente un recurso nuevo, en contra de lo que él lama "el modelo campesino liberal capitalista" representado en este caso por la oferta de PROCEDE-PRODECOM.

En el contexto actual, la tierra ya no es sólo un recurso agrícola, el territorio de Mezcala ha adquirido un valor mayor como "paisaje", "naturaleza", y tiene otros valores anexos como "historia" y "cultura”. Y eso se puede gestionar de una manera acorde a los intereses de los mezcalenses y sin que signifique atentar contra la historia y la identidad que han permitido llegar a esta situación. Se puede ir más allá del turismo y buscar insertarse en la globalización como indígenas cocas de una forma no "deficitaria", como ha sido históricamente. La apuesta es darle la vuelta a los contenidos históricos de la condición indígena a partir de dar nuevo sentido a la construcción histórica de la comunidad, ahora dentro un contexto globalizado.

\section{BiBLIOGRAFÍA}

Aguirre Beltrán, Gonzalo, Regiones de Refugio. El desarrollo de la comunidad y el proceso dominical en Mestizoamérica, Obra Antropológica, Ix, $1^{\text {a }}$ ed., 1967, México, Fondo de Cultura Económica, 1991.

Aguirre, Manuel J., Mezcala, la isla indómita, Guadalajara, Ediciones Estudiante, 1966. 
Alonso, Jorge, "La persistente defensa de la autonomía del pueblo de Mezcala”, ponencia presentada en el Simposio ¿Qué tan público es el espacio público en México?, Universidad Veracruzana, Xalapa, 27-28 noviembre 2008

ArCher, Christon I., "The Indian Insurgents of Mezcala Island on the Lake Chapala Front 1812-1816”, en Susan Schroerder, ed., Native Resistance and the Pax Colonial in New Spain, University of Nebraska, 1998.

Arévalo, Yohanna, Prácticas indigenistas y relaciones interétnicas en Jalisco, Tesis de Maestría en Antropología Social, Guadalajara, CIEsAs Occidente-Sureste, 2007.

Arias, Patricia, Del arraigo a la diáspora: dilemas de la familia rural, México, Porrua, UdeG, 2009.

Baitenmann, Helga, "Las paradojas de las conquistas revolucionarias: municipio y reforma agraria en el México contemporáneo", Gestión y Política Pública, vol. X, núm. 1, primer semestre 2001. , "Reforma agraria y ciudadanía en México", en Francisco Javier Gómez Carpinteiro, ed., Paisajes mexicanos de la reforma agraria. Homenaje a William Roseberry, Zamora, El Colegio de Michoacán, Benemérita Universidad de Puebla, CONACYT, 2007. Bastos, Santiago Cultura, pobreza y diferencia étnica en ciudad de Guatemala, Tesis de Doctorado en Ciencias Sociales, Guadalajara, CIESAS, UdeG, 2000.

, "La ideología multicultural en la Guatemala del cambio de milenio", en Mayanización y vida cotidiana. La ideología multicultural en la sociedad guatemalteca, vol. 1, Santiago Bastos y Aura Cumes, coords., Guatemala, FLACso, cIRMA Cholsamaj, 2007.

,"Mezcala ante la globalización: renovando los amarres de la historia”, en Juan Cajas, ed., Migración, procesos productivos, identidady estigmas sociales, México, Juan Pablos Editor, Universidad Autónoma del Estado de Morelos, 2010a.

, "Memoria, identidad y acción social: Mezcala y su Isla en la historia”, ponencia presentada en el Seminario La Comunidad Coca de Mezcala: los Pueblos Indígenas 200 años después de la Independencia, Guadalajara, CIESAs Occidente, 29 de octubre 2010. 
Baus de Czitromn, Carolyn, Tecuexes y Cocas. Dos grupos de la región Jalisco en el siglo XVI, Colección científica, 112, México, INAH, 1982.

BengoA, José, La emergencia indígena en América Latina, México, FCE, 2000.

Besserer, Federico, Topografias Transnacionales. Una geografia para el estudio de la vida transnacional, México, Universidad Autónoma Metropolitana Unidad Iztapalapa, Plaza y Valdés, 2002.

Bofill, Silvia, "Negociando el interés común: Poder conflicto y reciprocidad en San Juan Nuevo, Michoacán”, Relaciones. Estudios de Historia y Sociedad, núm. 89, invierno, Zamora, El Colegio de Michoacán, 2002.

Burguete, Araceli, "Autonomía: la emergencia de un nuevo paradigma en las luchas por la descolonización en América Latina”, en La autonomía a debate. Autogobierno indígena y Estado plurinacional en América Latina, M González, A Burguete y P. Ortiz, coords., Quito, FLACSO, GTZ, IWGIA, CIESAS, UNICH, 2010.

CÁrdenas, Elisa, "Prólogo", en Rosa María Castillero, Mezcala: expresión de un pueblo indigena en el periodo colonial. Vicisitudes y fortalezas, Guadalajara, Universidad de Guadalajara, 2006.

Castañeda, Carmen, Los pueblos de la Ribera del Lago de Chapala y la isla de Mezcala durante la independencia (1812-1816), Guadalajara, Gobierno del Estado de Jalisco, 2005.

Castillero, Rosa María, Mezcala: expresión de un pueblo indígena en el periodo colonial. Vicisitudes y fortalezas, Guadalajara, Universidad de Guadalajara, 2006.

De Ita, Ana "México: impactos del Procede en los conflictos agrarios y la concentración de la tierra", versión pdf http://www.landaction.org/gallery/Mon\%20PaperMEXICospan.pdf, 2003.

De la Peña, Guillermo, "Apuntes sobre los indigenismos en Jalisco", Estudios del Hombre, núm. 13-14.

, Culturas indígenas de Jalisco, Serie Las Culturas Populares de Jalisco, Guadalajara, Secretaría de Cultura, Gobierno del Estado de Jalisco, 2006.

, "Pepe Lameiras, los indígenas y el indigenismo", en Presencia de José Lameiras en la antropología mexicana, José Eduardo 
Zárate Hernández, ed., Zamora, El Colegio de Michoacán, 2008.

DíAz-Polanco, Héctor, Elogio de la diversidad. Globalización, multiculturalismo y etnofagia, México, Siglo XXI Editores, 2006.

DieTz, Gunther, "La comunidad acechada. La región purhépecha bajo el impacto del indigenismo", Relaciones. Estudios de Historia y Sociedad, núm. 78, primavera, Zamora, El Colegio de MIchoacán, 1999.

EsCalona, Jose Luis, "Reconstrucción de la etnicidad y transformaciones sociales", en Andrew Roth, ed., Recursos contenciosos. Ruralidad y reformas liberales en México, Zamora, El Colegio de Michoacán, 2004.

Florescano, Enrique, Memoria mexicana, México, Fondo de Cultura Económica, 1999.

Garibay, Claudio, Comunalismos y liberalismos campesinos. Identidad comunitaria, empresa social forestal y poder corporado en el México contemporáneo, Zamora, El Colegio de Michoacán, 2008.

GiL, Rocío, Fronteras de pertenencia. Hacia la construcción del bienestar y el desarrollo comunitario transnacional de Santa Maria Tindú, Oaxaca, México, Juan Pablos Editor, uAM, 2006.

Gómez Carpinteiro, Francisco Javier, "Recursos del pasado. Acción colectiva y sujetos posrevolucionarios en el contexto neoliberal", en Recursos contenciosos. Ruralidad y reformas liberales en México, Andrew Roth, ed., Zamora, El Colegio de Michoacán, 2004.

Hale, Charles, "Más que un indio". Ambivalencia racial y multiculturalismo neoliberal en Guatemala, Guatemala, Asociación para el Avance de las Ciencias Sociales en Guatemala, 2007.

Hernández, Adriana, El pueblo de Mezcala y los efectos de la degradación ambiental del lago de Chapala, Tesis de Maestría en Antropología Social, Guadalajara, CIESAs Occidente-Sureste, 2000.

Hernández, Rosalva Aída, Sarela Paz y María Teresa Sierra, El Estado y los indígenas en tiempos del PAN: Neoindigenismo, legalidad e identidades, México, CIEsAs, Porrúa, 2004.

KNIGHT, Alan, "La política agraria en México desde la Revolución", en Estructuras y formas agrarias en México, del pasado al presente, 
Antonio Escobar y Teresa Rojas, coords., México, CIESAS, RAN, 2001.

LameIras, José, El Tuxpan de Jalico. Una identidad danzante, Zamora, El Colegio de Michoacán, 1990.

LeYva, Xochitl, “¿Antropología de la ciudadanía?...étnica. En construcción desde América Latina”, Liminar. Estudios Sociales y Humanísticos, año 5, vol. V, núm. 1, junio 2007.

Leyva, Xóchitl, Araceli Burguete y Shannon Speed, coords., Gobernar (en) la diversidad: experiencias indígenas desde América Latina. Caminando hacia la investigación descolonizada, CIESAs, FLACSO Guatemala, FLACSO Ecuador, 2008.

Lucio, Carlos et al., El pueblo nahua de Ayotitlán. Pasado, presente y perspectivas, Guadalajara, UdeG, UACI, Taller Editorial La Casa del Mago, 2008.

Martin, Aaron, "El manejo forestal contrastante en dos núcleos agrarios de la Reserva de la Biosfera", Relaciones. Estudios de Historia y Sociedad, núm. 89, invierno, Zamora, El Colegio de Michoacán, 2002.

Medina, Andrés, "Las comunidades corporadas del sur del Distrito Federal. Una primera mirada etnográfica”, en Miguel Lisbona, coord., La comunidad a debate. Reflexiones sobre el concepto de comunidad en el México contemporáneo, Zamora, El Colegio de Michoacán, Universidad de Ciencias y Artes de Chiapas, 2005.

Medina, Andrés, coord., La memoria negada de la ciudad de México: sus pueblos originarios, México, IIA-UNAM, UACM, 2007.

Moreno, Rocío, "La comunidad indígena coca de Mezcala, el sujeto de la historia en la defensa de la tierra", Tesis de Licenciatura en Historia, Guadalajara, Universidad de Guadalajara, 2008.

Muñoz Morán, Óscar, Permanencia en el tiempo. Antropología de la historia en la comunidad purhépecha de Sevina, Zamora, El Colegio de Michoacán, 2009(a).

"Informe-ensayo de la comunidad indígena de Mezcala. Lectura del manejo de la Historia que hacen sus habitantes", Informe de trabajo, 2009(b).

Muñoz, Óscar y Santiago Bastos, “'Los insurgentes de Mezcala’ (1812-1816). Conflictos internos y externos ante la celebración 
del Bicentenario", ponencia presentada en el I Foro Editorial de Estudios Hispánicos y Americanistas. España y América en el Bicentenario de las Independencias, España, Universidad Jaume I. Castellón, del 21 al 23 de abril 2010.

Navarro SÁnchez, Salvador, La isla de Mezcala. La gesta olvidada, Guadalajara, Editorial Ágata, 1999.

OchoA, Álvaro, Los insurgentes de Mezcala, Zamora, El Colegio de Michoacán, 1985.

, Los insurrectos de Mezcala y Marcos, Zamora, El Colegio de Michoacán, 2006.

Pérez Verdía, Luis, Apuntes Históricos sobre la Guerra de la Independencia en Jalisco, Guadalajara, I.T.G, 1953.

Roseberry, William, “Para calmar los ánimos de los vecinos de este lugar': comunidad y conflicto en el Pátzcuaro porfiriano”, Relaciones. Estudios de Historia y Sociedad, núm. 100, Zamora, El Colegio de Michoacán, 2004.

Roth, Andrew, Elizabeth Martínez y Manuel Sosa, “'A nombre de la comunidad'. Política étnica y reforma neoliberal en la Meseta P'urhépecha”, en Andrew Roth, ed., Recursos contenciosos. Ruralidad y reformas liberales en Mèxico, Zamora, El Colegio de Michoacán, 2004.

Sieder, Rachel, ed., Multicuturalism in Latin America. Indigenous Rights, Diversity and Democracy, Londres, Palgrave Macmillan, Institute of Latin American Studies, 2002.

VELÁsquez HeRnández, Emilia, "Distintas formas de acercamiento a la historia local: la relación entre pasado y presente en una comunidad indígena del Sur de Veracruz", en Andrew Roth, ed., Recursos contenciosos. Ruralidad y reformas liberales en México, Zamora, El Colegio de Michoacán, 2004.

Warman, Arturo, Los campesinos: hijos predilectos del régimen, México, Nuestro Tiempo, 1972.

, Los indios mexicanos en el umbral del milenio, México, Fondo de Cultura Económica, 2003(a).

"La reforma agraria mexicana: una visión de largo plazo", FAO Document Repository, versión pdf http://www.fao.org/DOCREP/006/J0415T/j0415t09.htm, 2003(b). 
Wolf, Eric, "Closed Corporate Peasant Communities in Mesoamerica and Central Java", Southwestern Journal of Anthropology, vol. 1, núm. 13, 1957.

ZÁrate, Jose Eduardo, Los señores de utopía, Zamora, El Colegio de Michoacán, 1996.

, "La comunidad imposible", en Miguel Lisbona, coord., $L a$ comunidad a debate. Reflexiones sobre el concepto de comunidad en el México contemporáneo, Zamora, El Colegio de Michoacán, Universidad de Ciencias y Artes de Chiapas, 2005.

Zendejas, Sergio y Pieter DE VRIEs, eds., Las disputas por el México rural, 2 vols., Zamora, El Colegio de Michoacán, 1998.

\section{Documentos}

Resolución Presidencial de reconocimiento y Titulación de bienes comunales del poblado "MEzCALA", municipio de Poncitlán, Jalisco, Registro Agrario Nacional, 18 agosto 1971.

Acta de Reconocimiento y Titulación de bienes comunales poseídos por la comunidad indígena "MEzCALA", Municipio de Poncitlán, Jalisco, 17 octubre 1974.

Acta de Deslinde y Amojonamiento Definitivo, 4 de septiembre de 1997.

Declaración de Mezcala en defensa de la Madre Tierra y la autonomía indígena, Consejo Nacional Indígena, Mezcala 19 de noviembre de 2006.

Declaratoria de Mezcala, Asamblea General de Comuneros de la Comunidad Indígena de Mezcala, 3 febrero de 2008.

El pueblo coca de Mezcala. Una historia de lucha, trifoliar, 2008.

Estatuto Interno Comunidad Indígena Coca Mezcala de La Asunción, Municipio De Poncitlán, Jalisco, Comunidad Indígena de Mezcala, Mezcala, 7 de junio de 2009.

Los coca de Mezcala siguen vivos, Rocío Moreno, Manuel Jacobo y José Godoy, Hojarasca, 115, noviembre 2006.

Mezcala, un pueblo coca en la defensa de su memoria, Rocío Moreno. Revista Contradecir desde abajo, febrero 2009, http://contradecir.wordpress.com/2009/02/15mezcala-un-pueblo-coca-enla-defensa-de-su-memoria/ 
Plan de Desarrollo Urbano del Centro de población de Mezcala de la Asunción, Gaceta, Información con sentido. Órgano informativo del Gobierno Municipal de Poncitlán, núm. 2, noviembre 2006. Título Primordial, Copia mecanografiada y autenticada en La Barca, 6 de diciembre de 1899.

Ley sobre los Derechos y el Desarrollo de los Pueblos y las Comunidades Indígenas del Estado de Jalisco, Congreso del Estado de Jalisco, 30 diciembre 2006.

FECHA DE RECEPCIÓN DEL ARTículo: 15 de julio de 2010

FECHA DE ACEPTACIÓN Y RECEPCiÓN DE LA VERSIÓN FINAL: 10 de enero de 2011 